\title{
Glucocorticoid-dependent stimulation of adiposity and appetite by a ghrelin mimetic in the rat
}

\author{
Y L Tung, A K Hewson and S L Dickson \\ Department of Physiology, University of Cambridge, Downing Street, Cambridge CB2 3EG, Cambridge, UK \\ (Correspondence should be addressed to S L Dickson, Department of Physiology, Gothenburg University, Medicinaregatan 9, Box 434, SE-405 30, \\ Gothenburg, Sweden; Email: Suzanne@medic.gu.se)
}

(S L Dickson is now at Gothenburg University, Sweden)

\begin{abstract}
Objective: Chronic administration of GH secretagogues (GHSs) induces a state of positive energy balance in rodents by a GH-independent mechanism. Here we sought to determine to what extent the GHS effects to increase food intake and increase fat accumulation are glucocorticoid-dependent. Design: The effects of twice-daily s.c. injections of GH-releasing peptide-6 (GHRP-6) $(250 \mu \mathrm{g} / \mathrm{kg})$ for 2 weeks on body weight, food intake and fat pad weight were determined in both adrenalectomised (ADX) rats (with or without basal corticosterone replacement) and adrenal-intact rats.

Results: All GHS-injected rats had a significantly increased body weight at the end of 2 weeks of treatment compared with saline controls. However, increased fat accumulation was only seen in adrenalintact rats, with a $15 \%$ increase in s.c. inguinal $(P<0.05$ vs saline controls) and $20 \%$ increase in visceral mesenteric $(P<0.05)$ fat pad weights following GHS treatment. The increased body weight observed in ADX rats following GHS treatment was not due to increased fat mass or increased weight of other organs measured. Food intake was increased for up to $7 \mathrm{~h}$ following a single injection of GHRP-6 in both the adrenal-intact $(P<0.01)$ and corticosterone-replacement groups $(P<0.05)$. This stimulating effect on food intake was not observed at any time point in the ADX rats without corticosterone replacement.

Conclusion: These data suggest that GHS-induced body weight gain is glucocorticoid-independent. However, basal levels of glucocorticoids are permissive for the GHS-induced increase in food intake whilst activation of the hypothalamo-pituitary-adrenal axis appears to contribute to the GHSinduced accumulation of fat mass.
\end{abstract}

European Journal of Endocrinology 150 905-911

\section{Introduction}

The growth hormone (GH) secretagogues (GHSs) were initially identified and developed as a consequence of their potent GH-releasing activity (1). Although the first GHS was identified in the early 1980, the fataccumulating effects of these compounds have only recently become apparent, perhaps due to the fact that GHS-induced GH secretion was anticipated to induce lipolysis. Paradoxically, chronic treatment with GHS or ghrelin, the first identified endogenous ligand for the cloned GHS receptor (2), to rodents results in a positive energy balance by increasing appetite and fat accumulation $(3,4)$. This effect to increase fat mass is clearly GH-independent as fat accumulation persists in GH-deficient (lit/lit) mice given chronic GHS (3) or ghrelin treatment (4). More recently, a role for ghrelin in promoting a positive energy balance in humans has been suggested. This includes the demonstration of a preprandial rise and postprandial fall in circulating ghrelin levels $(5,6)$.

Several mechanisms may contribute to the increased fat accumulation induced by chronic GHS/ghrelin treatment. These include an increase in food intake (7-10), a decrease in energy expenditure (9) and altered nutrient utilisation with an increase in carbohydrate utilisation rather than fat, thus encouraging fat storage (4). Here we explored the possibility that activation of the hypothalamo-pituitary-adrenal (HPA) axis by GHSs $(11,12)$ contributes to their fataccumulating effect. The HPA axis has a critical role in the regulation of energy balance. An increased appetite is associated with glucocorticoid excess (13) or glucocorticoid administration to normal volunteers (14). Conversely, removal of glucocorticoids by adrenalectomy (ADX) reduces hyperphagia and body weight in several animal models of obesity including $o b / o b$ mice (15) and $f a / f a$ rats (16), ventromedial nucleus 
lesion-induced obesity (17), and also prevents obesity induced by chronic central neuropeptide Y (NPY) infusion in normal rats (18). Since peripheral glucocorticoid replacement in these ADX animal models reverses the effects of ADX in a dose-dependent manner (19-21), this suggests that the presence of glucocorticoids is a prerequisite for full development of many models of obesity.

In the present study we sought to determine whether the effects of GHS administration to increase fat accumulation and/or to increase food intake persist in ADX rats, with or without glucocorticoid replacement.

\section{Materials and methods}

\section{Animals and surgery}

Adult female Wistar rats (180-220g body weight) were obtained from Charles River Ltd, Kent, UK. Animals were housed in a temperature-controlled environment $\left(21-22^{\circ} \mathrm{C}\right)$ on a light-darkness schedule with lights on from 0700 to $1900 \mathrm{~h}$. Before experimental procedures were undertaken, all animals were housed in groups of four for at least 1 week following arrival at the Animal Unit. All animals were given free access to rat chow (RM-1; Special Diets Services, Essex, UK) and water unless otherwise stated. All experiments were performed in accordance with the UK Scientific Procedures Act (1986).

Bilateral ADX was performed under tribromoethanol/amyl hydrate anaesthesia (Avertin, $1 \mathrm{ml} / 100 \mathrm{~g}$ body weight, i.p.). Through a dorsal midline incision, small incisions were made through the muscle layer below the rib cage on each flank. Adrenal glands from both sides were isolated by blunt dissection and removed in their capsules. Following ADX, rats were provided with $0.9 \%$ saline in place of water to maintain electrolyte balance. For half the ADX rats, the saline was supplemented with corticosterone $(25 \mathrm{mg} / \mathrm{l})$ (SigmaAldrich) calculated to give a basal level of plasma corticosterone (22). Corticosterone replacement was given in the drink as this method has been shown to mimic the normal circadian pattern of glucocorticoid secretion (23).

ADX rats were fed freely and were healthy in appearance and behaviour. The controls for the experiment did not include a sham-operated group due to restrictions associated with the licence for animal experimentation (Home Office, UK). Following surgery, rats were allowed to recover and were handled daily for 1 week. Completeness of ADX was verified by checking for residual adrenal tissue at post-mortem and by measuring plasma corticosterone levels on samples obtained from rats at the end of the study.

\section{Two weeks of GHRP-6 treatment}

Rats were divided into six groups: Intact Saline $(n=6)$, Intact GHS $(n=6)$, ADX Saline $(n=6)$, ADX GHS $(n=5)$, ADX-CORT Saline $(n=6)$ and ADX-CORT GHS $(n=7)$. For GHS treatment, rats were injected s.c. twice daily with GHRP-6 $(2 \times 250 \mu \mathrm{g} / \mathrm{kg}$ body weight $)$ (Bachem, Merseyside, UK). Saline-treated rats received an equal volume $(0.2 \mathrm{ml})$ of saline vehicle. Morning injections were performed between 0900 and $1000 \mathrm{~h}$ daily and afternoon injections between 1600 and $1700 \mathrm{~h}$. For acute food intake measurement, on day 1, following both morning and the afternoon injections, rats were returned to their cages with free access to a pre-weighed amount of food. Food intake was measured at 1,4 and $7 \mathrm{~h}$ after each injection. During the 2 week treatment period, daily body weight and food intake were measured in the morning within $1 \mathrm{~h}$ of the same time each day. Food intake was measured as the change in weight, to the nearest $0.1 \mathrm{~g}$, of a pre-weighed amount of chow pellets placed in the food holder.

Rats were killed by an overdose of $120 \mathrm{mg} / \mathrm{kg}$ body weight i.p. sodium pentobarbitone (Sagatal; Rhône Mérieux, Harlow, Essex, UK). Subcutaneous and visceral fat pads (i.e. mesenteric, retroperitoneal and parametrial) were dissected bilaterally where appropriate. The brain, heart, liver, and kidneys were also dissected. All tissues were weighed separately and expressed as per cent of body weight.

Plasma corticosterone was measured from blood collected by cardiac puncture at the time of sacrifice. It was analysed using an ${ }^{125}$ I RIA Kit (ImmunChem Double Antibody; ICN Biomedicals, Inc., Costa Mesa, CA, USA). All samples were assayed in duplicate and the detection limits of the assay were $25-1000 \mathrm{ng} / \mathrm{ml}$.

\section{Statistical analysis}

Descriptive statistical results are shown as means \pm S.E.M. Means were compared by two-way ANOVA followed by Tukey's pairwise multiple comparison procedure using SigmaStat statistical software.

\section{Results}

\section{Plasma corticosterone}

ADX reduced the plasma concentration of corticosterone to a value below the limit of detection of the assay, whereas levels in intact rats were $348.1 \pm 45.0 \mathrm{ng} / \mathrm{ml}$. Supplementation of the drinking water of $\mathrm{ADX}$ rats with corticosterone resulted in plasma corticosterone levels of $182.9 \pm 32.8 \mathrm{ng} / \mathrm{ml}$, which was $\sim 60 \%$ of that seen in intact rats. GHS treatment did not alter corticosterone levels in any group (Intact, ADX or ADX-CORT) when compared with saline-injected controls.

\section{Body weight}

At the time of ADX the mean weight of rats was identical for all six groups of rats, averaging 
$213 \pm 3$ g. Following surgery, the ADX-CORT group appeared to recover better than the ADX group; regardless of the difference in body weight at day 0 of treatment, twice-daily GHRP-6 injection caused a significant increase in body weight gain compared with saline-treated rats in all groups (Fig. 1A and B).

\section{Body fat}

In ADX rats without corticosterone replacement, inguinal, retroperitoneal and parametrial fat pads weights were reduced compared with intact rats $(P<0.01$; Table 1, Fig. 2). The ADX-CORT group showed a similar but less pronounced reduction in fat pad weight, consistent with corticosterone's fat-accumulating effects.

Following 2 weeks of twice-daily injections of GHRP6 to adrenal-intact rats, subcutaneous inguinal fat was
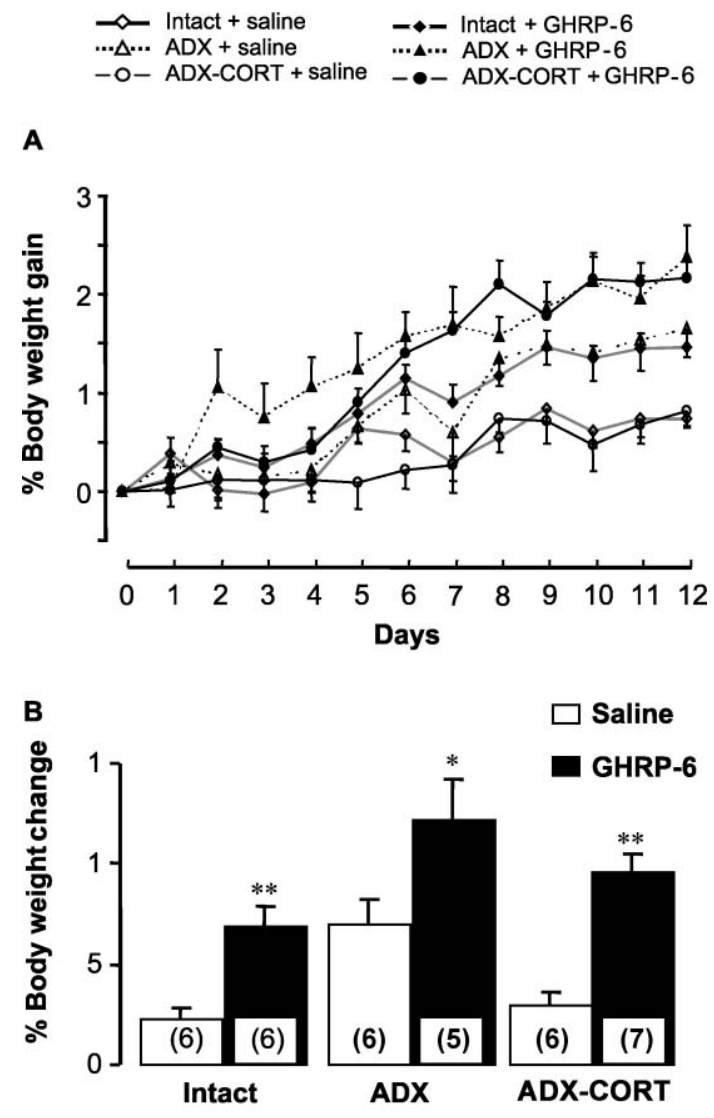

Figure 1 Body weight change (means \pm S.E.M.) following twicedaily subcutaneous injection of GHRP-6 (500 $\mu \mathrm{g} / \mathrm{kg}$ body weight/ day for 2 weeks) or saline vehicle to adrenal-intact (Intact), adrenalectomised (ADX) or adrenalectomised rats with a basal level of corticosterone replacement (ADX-CORT). Data are expressed as (A) daily weight gain normalised to day 0 of treatment and $(B)$ total weight gain at the end of the study as per cent change from day 0 of treatment. ${ }^{\star} P<0.05$, ${ }^{*} P<0.01$ denote significance compared with the saline-treated control rats using ANOVA followed by Tukey's post-hoc test. The numbers in parentheses indicate the number of rats in each experimental group. increased by 15\% and mesenteric fat increased by $20 \%$ (Table 1, Fig. 2). It is noteworthy that these GHSinduced fat-accumulating effects in rats are not as marked as those observed previously in mice (3). Nonetheless, the fat-accumulating effect of GHRP- 6 observed in the inguinal and mesenteric fat pads of the adrenalintact rats was not observed in the ADX groups, with or without corticosterone replacement (Table 1, Fig. 2).

Organ weight measurement demonstrated that the increased body weight following chronic exposure to GHS does not appear to be due to a disproportionate increase in the weight of any of the dissected organs (brain, heart, liver, kidney; data not shown).

\section{Food intake}

A single s.c. injection of GHRP-6 stimulated food intake in the adrenal-intact rats at 1,4 and $7 \mathrm{~h}$ in the light photoperiod (Fig. 3A). A similar pattern was also observed in the ADX groups with corticosterone replacement, although the trend only reaches significance at the seventh hour after injection. The acute stimulating effect of GHRP-6 on appetite was not observed at any time point in the ADX rats. For the afternoon injection (Fig. 3B), $1 \mathrm{~h}$ food intake was only significantly increased in the adrenal-intact group. This appetiteinducing effect of peripheral GHRP-6 was lost on entering the dark photoperiod, as the $4 \mathrm{~h}$ food intake (which was measured $1 \mathrm{~h}$ into the dark cycle) was not significantly different between GHRP-6 treatment and the saline-control groups. Thus, average daily food intake was not different between GHRP-6 and saline treatment (Fig. 4).

\section{Discussion}

The present study sought to determine to what extent GHS-induced food intake and fat accumulation are mediated by or dependent upon glucocorticoids. The first indication that this might be the case came from studies showing that hypophysectomised rats, or indeed ADX rats, do not increase food intake or fat accumulation in response to 1 week of GHRP-2 treatment (24). Here we extended these observations to include ADX rats with basal corticosterone replacement for 2 weeks, such that the degree of glucocorticoid-dependence of the effects may become apparent.

We show that ADX rats with basal corticosterone replacement have a GHRP-6-induced feeding response that is similar to adrenal-intact rats. This is in contrast to ADX rats without corticosterone replacement, in which the positive effects of GHRP- 6 on acute food intake were not evident. Thus, glucocorticoids appear to be permissive for the short-term effect of GHS to increase food intake. A slightly different picture emerges for the role of glucocorticoids in the fataccumulating effects of GHS. The GHRP-6-induced 
Table 1 Relative weights (means \pm S.E.M.) of dissected fat pads (expressed as per cent of body weight) following twice-daily s.C. injection of GHRP-6 (500 $\mu \mathrm{g} / \mathrm{kg}$ body weight/day for 2 weeks) or saline vehicle to adrenal-intact (Intact), adrenalectomised (ADX) or adrenalectomised rats with a basal level of corticosterone replacement (ADX-CORT). For each rat inguinal, mesenteric, retroperitoneal and parametrial fat pads were removed bilaterally and weighed separately. Total fat pad data gives the pooled data from all dissected fat pads.

\begin{tabular}{|c|c|c|c|c|c|}
\hline & Inguinal & Mesenteric & Retroperitoneal & Parametrial & Total \\
\hline Intact/Saline $(n=6)$ & $1.56 \pm 0.11$ & $1.17 \pm 0.04$ & $1.90 \pm 0.14$ & $1.27 \pm 0.13$ & $5.90 \pm 0.28$ \\
\hline Intact/GHS $(n=6)$ & $1.81 \pm 0.11^{*}$ & $1.38 \pm 0.10^{*}$ & $1.85 \pm 0.12$ & $1.27 \pm 0.07$ & $6.31 \pm 0.34$ \\
\hline ADX/Saline $(n=6)$ & $0.92 \pm 0.08^{\star * *}$ & $1.03 \pm 0.04$ & $0.75 \pm 0.02^{\star \star *}$ & $0.65 \pm 0.04^{\star * *}$ & $3.36 \pm 0.08^{* * *}$ \\
\hline $\mathrm{ADX} / \mathrm{GHS}(n=5)$ & $0.81 \pm 0.15^{\star \star \star}$ & $0.96 \pm 0.07$ & $0.73 \pm 0.13^{\star \star *}$ & $0.62 \pm 0.12^{\star * *}$ & $3.13 \pm 0.43^{* * *}$ \\
\hline ADX-CORT/Saline $(n=6)$ & $1.13 \pm 0.05^{\star \star}$ & $1.12 \pm 0.08$ & $1.02 \pm 0.09 * \star \star$ & $0.90 \pm 0.07^{\star \star}$ & $4.17 \pm 0.27^{\star * *}$ \\
\hline ADX-CORT/GHS $(n=7)^{\prime}$ & $1.15 \pm 0.08^{\star \star *}$ & $1.21 \pm 0.05$ & $1.09 \pm 0.05^{\star \star *}$ & $0.88 \pm 0.05^{\star \star}$ & $4.33 \pm 0.18^{* * *}$ \\
\hline
\end{tabular}

${ }^{\star} P<0.05,{ }^{* \star} P<0.01,{ }^{* \star \star} P<0.001$, significant differences between pairwise groups using two-way ANOVA followed by Tukey's post-hoc test.

increase in fat pad weight observed in intact rats was abolished in ADX rats, with or without basal corticosterone replacement. This would suggest that GHSinduced fat accumulation is, at least in part, dependent on increased levels of glucocorticoids.

The effects of ADX with and without glucocorticoid replacement on GHS-induced fat accumulation was determined by fat pad dissection. There were similar trends in fat pad weight for the visceral (retroperitoneal

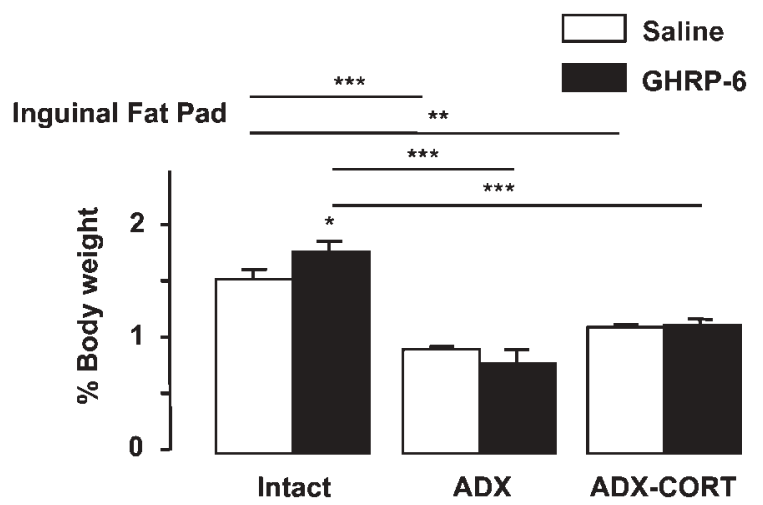

Mesenteric Fat Pad

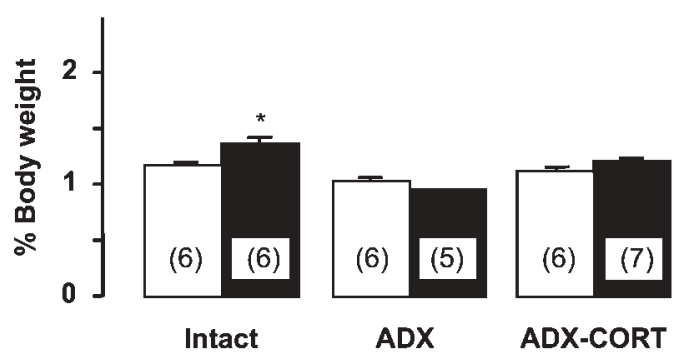

Figure 2 Relative weights (means \pm S.E.M.) of dissected fat pads (as per cent body weight) following twice-daily s.c. injection of GHRP-6 (500 $\mu \mathrm{g} / \mathrm{kg}$ body weight/day for 2 weeks) or saline vehicle to adrenal-intact (Intact), adrenalectomised (ADX) or adrenalectomised rats with a basal level of corticosterone replacement (ADX-CORT). Significant differences between pairwise groups are denoted as ${ }^{\star} P<0.05,{ }^{*} P<0.01,{ }^{* * \star} P<0.001$ 0.001 following ANOVA and Tukey's post-hoc test. The numbers in parentheses indicate the number of rats in each experimental group. and parametrial) fat pad depots and for the subcutaneous inguinal depots, suggesting that these measurements provide a good representation of overall changes in fat accumulation. As the fat-accumulating effect of GHS was abolished by ADX, with or without basal glucocorticoid replacement, it was surprising to
A Morning injection

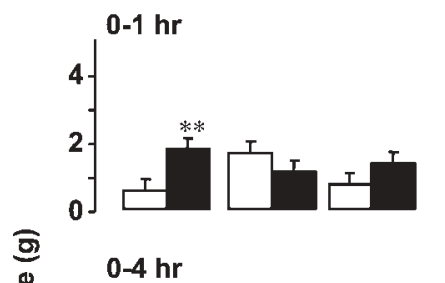

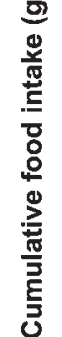$$
2
$$

\section{B Afternoon injection}

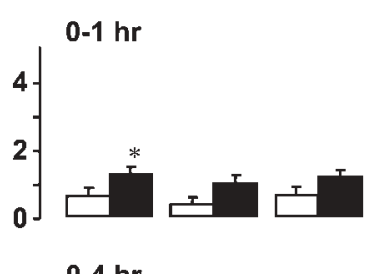

Figure 3 Cumulative food intake (means \pm S.E.M.) following a single s.c. injection of GHRP-6 ( $250 \mu \mathrm{g} / \mathrm{kg}$ body weight) or saline vehicle to adrenal-intact (Intact), adrenalectomised (ADX) or adrenalectomised rats with basal level of corticosterone replacement (ADX-CORT). Food intake was measured on day 1 of the experiment following both (A) morning (between 0900 and $1000 \mathrm{~h}$ ) and the (B) afternoon (between 1600 and $1700 \mathrm{~h}$ ) injections of either saline or GHRP-6. Cumulative food intake was measured at during the first $1 \mathrm{~h}(0-1 \mathrm{~h})$, during the first $4 \mathrm{~h}(0-4 \mathrm{~h})$ and during the first $7 \mathrm{~h}(0-7 \mathrm{~h})$ following the morning injection and at $0-1$ and $0-4 \mathrm{~h}$ following the afternoon injection. ${ }^{\star} P<0.05,{ }^{\star} * P<0.01$ denote significance after comparisons of GHRP-6- vs saline-treated rats, following ANOVA and Tukey's post-hoc test. The numbers in parentheses indicate the number of rats in each experimental group. 


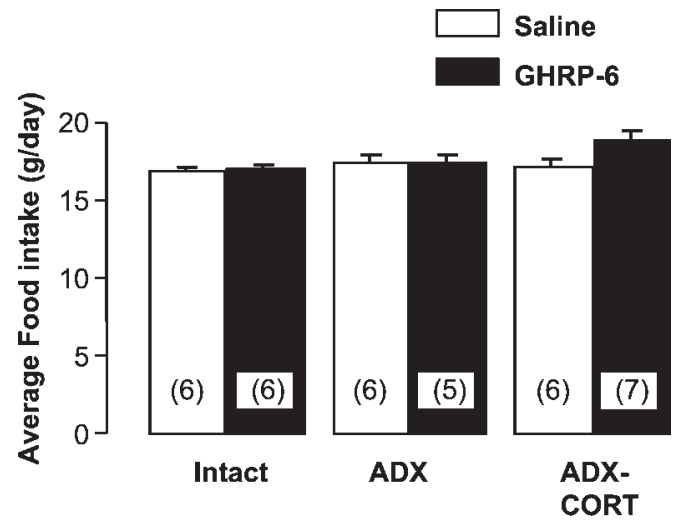

Figure 4 Food intake (means \pm S.E.M.) following twice-daily s.c. injection of GHRP-6 (500 $\mu \mathrm{g} / \mathrm{kg}$ body weight/day for 2 weeks) or saline vehicle to adrenal-intact (Intact), adrenalectomised (ADX) or adrenalectomised rats with a basal level of corticosterone replacement (ADX-CORT). No significant differences were observed following GHRP-6 injection compared with saline-treated control rats (ANOVA followed by pairwise multiple comparisons Tukey's test). The numbers in parentheses indicate the number of rats in each experimental group.

discover that ADX did not block the ability of GHS to increase body weight. Thus, total body weight gain induced by GHS appears to be glucocorticoid-independent. The mismatch between the GHS effects on body weight gain and fat accumulation in these ADX rats provides an indication that there is a fat-free component to the weight gain induced by GHS. This could reflect a GH-dependent stimulatory effect on bone and/or lean body mass (25).

In the present study, the acute effects of GHRP-6 on food intake were observed in adrenal-intact rats, and this orexigenic effect was significant up to $7 \mathrm{~h}$ following a single peripheral injection administered during the morning, a time when the animals are normally satiated. This feeding response was less pronounced following the afternoon injection as it was only significant at $1 \mathrm{~h}$ after injection. By $4 \mathrm{~h}$ after the afternoon injection (corresponding to $2000-2100 \mathrm{~h}$ ), the animals had entered the dark phase, a time when all rats increase their food intake. Thus, GHS/ghrelin-induced feeding appears to be influenced by the onset of the dark phase and may be masked at this time point by other feeding drives during normal nocturnal/hunger-induced food intake. This altered responsiveness to GHS between morning and afternoon injection may reflect changes in endogenous ghrelin secretion. In humans, for example, plasma ghrelin is highest preprandially in association with periods of hunger and are lower in the satiated state (5). Alternatively, it is possible that differences in responsiveness to exogenous GHS between morning and afternoon injections is dependent upon other satiety/hunger factors, such as leptin $(26,27)$, insulin (27) or even other endocrine signals that have a diurnal rhythm such as corticosterone (28).

Collectively, our data suggest that adrenal glucocorticoids are required (via a permissive mechanism) to allow ghrelin-induced food intake whilst ghrelin's adipogenic effects appear to be glucocorticoid-independent. This would suggest that ghrelin-induced fat accumulation is not dependent upon on its orexigenic effects but may rather reflect changes in energy expenditure (9), altered nutrient utilisation (4) and perhaps altered thermogenesis. Consistent with this hypothesis, ghrelin's effects to elicit a positive energy balance are thought to be independent of the orexigenic NPY, as demonstrated by the normal GHS effects on food intake in NPY knockout mice (4). Nevertheless, it seems likely that the stimulation of adrenal glucocorticoids is important for ghrelin's permissive effect on food intake, but this action is mediated by direct interaction with hypothalamic circuit sensitive to control of energy balance, such as the arcuate Agrp-containing neurons. Evidence supporting this include the study demonstrated that Agrp antibody or antagonist treatment in rats abolished the ghrelin stimulated increase in food intake (29).

The hypothalamic circuitry through which GHS/ghrelin operate to activate the HPA axis has not yet been fully clarified. The cloned GHS receptor $1 \mathrm{~A}$ is present in the hypothalamic paraventricular nucleus (PVN) $(30,31)$ where the corticotrophin-releasing hormone $(\mathrm{CRH})$ and arginine vasopressin (AVP) neurons that regulate corticosterone release are localised (32). Since ghrelin stimulated the release of both $\mathrm{CRH}$ and AVP from hypothalamic explants (33), it is possible that GHS activates these neurons directly to mediate the effects on the HPA axis. Co-administration of GHS together with AVP but not CRH produced an additive effect on corticosterone release, suggesting that GHS stimulate the HPA axis via an AVP-independent but CRH-dependent route (34). Consistent with this, ghrelin nerve terminals appear to have close synaptic contacts with $\mathrm{CRH}$ neurons in this region of the hypothalamus (35). On the other hand, glucocorticoids also appear to mediate at least some of their actions through the central NPY system (36). Since the interconnection of NPY neurons of the arcuate nucleus with the CRH and AVP of the PVN is well characterised (37), the activation of the HPA axis by GHS could be indirectly through the action of arcuate NPY-containing neurons.

Although well established that GHSs activate the HPA axis, reflected by acute adrenocorticotrophic hormone/corticosterone measurements following single GHS injections (38), to the best of our knowledge there are no studies showing elevated glucocorticoids following chronic GHS exposure. Indeed, in contrast to the findings reported after acute GHS administration, one clinical study demonstrates a decrease in serum cortisol after 16 weeks of GHS treatment (39). Although a tendency to reduced plasma corticosterone was also observed in this study following GHS treatment in the adrenal-intact rat, we did not detect any changes in plasma corticosterone levels following GHS treatment. This probably reflects the fact that plasma 
corticosterone concentration was measured in a single sample of trunk blood taken at the end of 2 weeks of exposure to GHS, and on the day of killing rats were not injected with GHRP-6.

Thus, the mechanisms underlying the GHS/ghrelininduced fat accumulation may not yet be fully determined but are clearly multi-faceted and include both acute effects on food intake $(7-10)$ and respiratory quotient (4). It now seems clear also that the fat-accumulating effects of GHS are glucocorticoiddependent.

\section{Acknowledgements}

This research was supported by the EC Fifth Framework (QLRT-1999-02038) and the Medical Research Council, UK.

\section{References}

1 Bowers CY, Momany FA, Reynolds GA \& Hong A. On the in vitro and in vivo activity of a new synthetic hexapeptide that acts on the pituitary to specifically release growth hormone. Endocrinology $19841141537-1545$.

2 Kojima M, Hosoda H, Date Y, Nakazato M, Matsuo H \& Kangawa K. Ghrelin is a growth-hormone-releasing acylated peptide from stomach. Nature $1999 \mathbf{4 0 2}$ 656-660.

3 Lall S, Tung LY, Ohlsson C, Jansson JO \& Dickson SL. Growth hormone $(\mathrm{GH})$-independent stimulation of adiposity by GH secretagogues. Biochemical and Biophysical Research Communications $2001280132-138$.

4 Tschöp M, Smiley DL \& Heiman ML. Ghrelin induces adiposity in rodents. Nature $2000 \mathbf{4 0 7} 908-913$.

5 Cummings DE, Purnell JQ, Frayo RS, Schmidova K, Wisse BE \& Weigle DS. A preprandial rise in plasma ghrelin levels suggests a role in meal initiation in humans. Diabetes 200150 $1714-1719$.

6 Tschöp M, Wawarta R, Riepl RL, Friedrich S, Bidlingmaier M, Landgraf R \& Folwaczny C. Post-prandial decrease of circulating human ghrelin levels. Journal of Endocrinological Investigation 200124 RC19-RC21.

7 Locke W, Kirgis HD, Bowers CY \& Abdoh AA. Intracerebroventricular growth-hormone-releasing peptide-6 stimulates eating without affecting plasma growth hormone responses in rats. Life Sciences $1995 \mathbf{5 6} 1347-1352$.

8 Torsello A, Luoni M, Schweiger F, Grilli R, Guidi M, Bresciani E, Deghenghi R, Muller EE \& Locatelli V. Novel hexarelin analogs stimulate feeding in the rat through a mechanism not involving growth hormone release. European Journal of Pharmacology 1998 360 123-129.

9 Wren AM, Small CJ, Ward HL, Murphy KG, Dakin CL, Taheri S, Kennedy AR, Roberts GH, Morgan DG, Ghatei MA \& Bloom SR. The novel hypothalamic peptide ghrelin stimulates food intake and growth hormone secretion. Endocrinology $2000 \mathbf{1 4 1}$ 4325-4328.

10 Wren AM, Seal LJ, Cohen MA, Brynes AE, Frost GS, Murphy KG, Dhillo WS, Ghatei MA \& Bloom SR. Ghrelin enhances appetite and increases food intake in humans. Journal of Clinical Endocrinology and Metabolism $2001865992-5995$.

11 Hickey GJ, Jacks TM, Schleim KD, Frazier E, Chen HY, Krupa D, Feeney W, Nargund RP, Patchett AA \& Smith RG. Repeat administration of the GH secretagogue MK-0677 increases and maintains elevated IGF-I levels in beagles. Journal of Endocrinology $1997152183-192$.
12 Thomas GB, Fairhall KM \& Robinson IC. Activation of the hypothalamo-pituitary-adrenal axis by the growth hormone (GH) secretagogue, GH-releasing peptide-6, in rats. Endocrinology $19971381585-1591$.

13 Orth DN. Corticotropin-releasing hormone in humans. Endocrine Reviews $199213164-191$.

14 Tataranni PA, Larson DE, Snitker S, Young JB, Flatt JP \& Ravussin E. Effects of glucocorticoids on energy metabolism and food intake in humans. American Journal of Physiology 1996271 E317-E325.

15 Makimura H, Mizuno TM, Roberts J, Silverstein J, Beasley J \& Mobbs CV. Adrenalectomy reverses obese phenotype and restores hypothalamic melanocortin tone in leptin-deficient ob/ob mice. Diabetes $2000491917-1923$.

16 Freedman MR, Stern JS, Reaven GM \& Mondon CE. Effect of adrenalectomy on in vivo glucose metabolism in insulin resistant Zucker obese rats. Hormone and Metabolic Research 198618 296-298.

17 Freedman MR, Horwitz BA \& Stern JS. Effect of adrenalectomy and glucocorticoid replacement on development of obesity. American Journal of Physiology 1986250 R595-R607.

18 Sainsbury A, Cusin I, Rohner-Jeanrenaud F \& Jeanrenaud B. Adrenalectomy prevents the obesity syndrome produced by chronic central neuropeptide Y infusion in normal rats. Diabetes $199746209-214$.

19 Castonguay TW, Dallman MF \& Stern JS. Some metabolic and behavioral effects of adrenalectomy on obese Zucker rats. American Journal of Physiology 1986251 R923-R933.

20 Freedman MR, Horwitz BA \& Stern JS. Effect of adrenalectomy and glucocorticoid replacement on development of obesity. American Journal of Physiology 1986250 R595-R607.

21 Tokuyama K \& Himms-Hagen J. Increased sensitivity of the genetically obese mouse to corticosterone. American Journal of Physiology 1987252 E202-E208.

22 Jacobson L, Akana SF, Cascio CS, Scribner K, Shinsako J \& Dallman MF. The adrenocortical system responds slowly to removal of corticosterone in the absence of concurrent stress. Endocrinology $19891242144-2152$.

23 Jacobson L, Akana SF, Cascio CS, Shinsako J \& Dallman MF. Circadian variations in plasma corticosterone permit normal termination of adrenocorticotropin responses to stress. Endocrinology $19881221343-1348$.

24 Tschöp M, Flora DB, Mayer JP \& Heiman ML. Hypophysectomy prevents ghrelin-induced adiposity and increases gastric ghrelin secretion in rats. Obesity Research $200210991-999$.

25 Svensson J, Lall S, Dickson SL, Bengtsson BA, Romer J, Ahnfelt-Ronne I, Ohlsson C \& Jansson JO. The GH secretagogues ipamorelin and GH-releasing peptide-6 increase bone mineral content in adult female rats. Journal of Endocrinology 2000165 569-577.

26 Tung YC, Hewson AK \& Dickson SL. Actions of leptin on growth hormone secretagogue-responsive neurones in the rat hypothalamic arcuate nucleus recorded in vitro. Journal of Neuroendocrinology $200113209-215$.

27 Hewson AK, Tung LY, Connell DW, Tookman L \& Dickson SL. The rat arcuate nucleus integrates peripheral signals provided by leptin, insulin, and a ghrelin mimetic. Diabetes 200251 3412-3419.

28 Atkinson HC \& Waddell BJ. Circadian variation in basal plasma corticosterone and adrenocorticotropin in the rat: sexual dimorphism and changes across the estrous cycle. Endocrinology $19971383842-3848$.

29 Nakazato M, Murakami N, Date Y, Kojima M, Matsuo H, Kangawa $\mathrm{K} \&$ Matsukura S. A role for ghrelin in the central regulation of feeding. Nature 2001409 194-198.

30 Bennett PA, Thomas GB, Howard AD, Feighner SD, Van der Ploeg LH, Smith RG \& Robinson IC. Hypothalamic growth hormone secretagogue-receptor (GHS-R) expression is regulated by growth hormone in the rat. Endocrinology $1997 \mathbf{1 3 8}$ $4552-4557$. 
31 Guan XM, Yu H, Palyha OC, McKee KK, Feighner SD, Sirinathsinghji DJ, Smith RG, Van der Ploeg LH \& Howard AD. Distribution of mRNA encoding the growth hormone secretagogue receptor in brain and peripheral tissues. Brain Research. Molecular Brain Research 199748 23-29.

32 Herman JP, Wiegand SJ \& Watson SJ. Regulation of basal corticotropin-releasing hormone and arginine vasopressin messenger ribonucleic acid expression in the paraventricular nucleus: effects of selective hypothalamic deafferentations. Endocrinology 1990 $1272408-2417$.

33 Wren AM, Small CJ, Fribbens CV, Neary NM, Ward HL, Seal LJ, Ghatei MA \& Bloom SR. The hypothalamic mechanisms of the hypophysiotropic action of ghrelin. Neuroendocrinology $2002 \mathbf{7 6}$ 316-324.

34 Thomas GB, Fairhall KM \& Robinson IC. Activation of the hypothalamo-pituitary-adrenal axis by the growth hormone (GH) secretagogue, GH-releasing peptide-6, in rats. Endocrinology $19971381585-1591$.

35 Cowley MA, Smith RG, Diano S, Tschöp M, Pronchuk N, Grove KL, Strasburger CJ, Bidlingmaier M, Esterman M, Heiman ML, Garcia-Segura LM, Nillni EA, Mendez P, Low MJ, Sotonyi P, Friedman JM, Liu H, Pinto S, Colmers WF, Cone RD \& Horvath
TL. The distribution and mechanism of action of ghrelin in the CNS demonstrates a novel hypothalamic circuit regulating energy homeostasis. Neuron 200337 649-661.

36 King BM. Glucocorticoids and hypothalamic obesity. Neuroscience and Biobehavioral Reviews 198812 29-37.

37 Wren AM, Small CJ, Fribbens CV, Neary NM, Ward HL, Seal LJ, Ghatei MA \& Bloom SR. The hypothalamic mechanisms of the hypophysiotropic action of ghrelin. Neuroendocrinology $2002 \mathbf{7 6}$ 316-324.

38 Thomas GB, Fairhall KM \& Robinson IC. Activation of the hypothalamo-pituitary-adrenal axis by the growth hormone (GH) secretagogue, GH-releasing peptide-6, in rats. Endocrinology $19971381585-1591$.

39 Rahim A, O’Neill PA \& Shalet SM. The effect of chronic hexarelin administration on the pituitary-adrenal axis and prolactin. Clinical Endocrinology $1999 \mathbf{5 0} 77-84$.

Received 8 December 2003

Accepted 20 February 2004 